\title{
Rule out of acute aortic dissection with plasma matrix metalloproteinase 8 in the emergency department
}

\author{
Francesca Giachino1, Marilena Loiacono², Manuela Lucchiari², Maria Manzo², Stefania Battista', Elisa Saglio', \\ Enrico Lupia', Corrado Moiraghi', Emilio Hirsch ${ }^{3}$, Giulio Mengozzi ${ }^{2}$ and Fulvio Morello ${ }^{1,3^{*}}$
}

\begin{abstract}
Introduction: Matrix metalloproteinases (MMPs) are involved in aortic pathophysiology. Preliminary studies have detected increased plasma levels of MMP8 and MMP9 in patients with acute aortic dissection (AAD). However, the performance of plasma MMP8 and MMP9 for the diagnosis of AAD in the emergency department is at present unknown.

Methods: The levels of MMP8 and MMP9 were measured by ELISA on plasma samples obtained from 126 consecutive patients evaluated in the emergency department for suspected AAD. All patients were subjected to urgent computed tomography $(\mathrm{CT})$ scan for final diagnosis.

Results: In the study cohort ( $N=126)$, AAD was diagnosed in 52 patients and ruled out in 74 patients. Median plasma MMP8 levels were 36.4 (interquartile range 24.8 to 69.3 ) $\mathrm{ng} / \mathrm{ml}$ in patients with AAD and 13.2 (8.1 to 31.8) $\mathrm{ng} / \mathrm{ml}$ in patients receiving an alternative final diagnosis $(P<0.0001)$. Median plasma MMP9 levels were 169.2 (93.0 to 261.8$) \mathrm{ng} / \mathrm{ml}$ in patients with $A A D$ and $80.5(41.8$ to 140.6$) \mathrm{ng} / \mathrm{ml}$ in patients receiving an alternative final diagnosis $(P=0.001)$. The area under the curve $(A \cup C)$ on receiver-operating characteristic $(R O C)$ analysis of MMP8 and MMP9 for the diagnosis of AAD was respectively 0.75 and 0.70 , as compared to 0.87 of D-dimer. At the cutoff of $3.6 \mathrm{ng} / \mathrm{ml}$, plasma MMP8 had a sensitivity of $100.0 \%$ (95\% Cl, 93.2\% to $100.0 \%$ ) and a specificity of $9.5 \%$ (95\% Cl, $3.9 \%$ to $18.5 \%$ ) and ruled out AAD in $5.6 \%$ of patients. Combination of plasma MMP8 with D-dimer increased the AUC on ROC analysis to 0.89 . Presence of MMP8 $<11.0 \mathrm{ng} / \mathrm{ml}$ and D-dimer $<1.0 \mathrm{or}<2.0 \mu \mathrm{g} / \mathrm{ml}$ provided a negative predictive value of $100 \%$ and ruled out AAD in $13.6 \%$ and $21.4 \%$ of patients respectively.

Conclusions: Low levels of plasma MMP8 can rule out AAD in a minority of patients. Combination of plasma MMP8 and D-dimer at individually suboptimal cutoffs could safely rule out AAD in a substantial proportion of patients evaluated in the emergency department.
\end{abstract}

\section{Introduction}

The prompt identification of acute aortic dissection (AAD) in the emergency department (ED) is paramount to reduce morbidity and mortality in affected patients, as diagnostic delays lead to inappropriate clinical management and defer life-saving treatments such as cardiothoracic surgery and/or endovascular repair [1,2]. However, the diagnosis of AAD in the ED is highly challenging,

\footnotetext{
* Correspondence: fulvio.morello@gmail.com

'S.C. Medicina d'Urgenza, Molinette Hospital, A.O. Città della Salute e della

Scienza di Torino, Corso Bramante, 88, 10126 Torino, Italy

Full list of author information is available at the end of the article
}

because AAD is rare (2-4 cases per 100,000 individuals per year) and clinically heterogeneous at presentation [3-5]. Currently, the diagnostic approach to suspected AAD relies on imaging techniques such as computed tomography (CT) scan and transesophageal echocardiography, which nonetheless require thorough pretest clinical selection and may not be immediately available in all EDs [2]. Therefore, identification of blood markers supporting or refusing the diagnosis of AAD would provide a major breakthrough. D-dimer, a well-established marker of vascular thrombosis, has shown high sensitivity but low specificity for the diagnosis of AAD [6,7]. Ideal
C Biomed Central 
diagnostic markers of AAD would be components of the aortic wall released into the bloodstream upon acute aortic damage, similar to circulating troponin for acute myocardial damage. On these grounds, different aortic proteins have been examined, such as smooth muscle myosin heavy chain, soluble elastin fragments and calponin [8-10]. However, none of them has been introduced into clinical practice so far.

Matrix metalloproteinases (MMPs) constitute a large family of calcium and zinc-dependent endopeptidases that degrade the extracellular matrix [11]. MMPs are key molecular mediators of aortic disease and contribute to the landmark feature of extracellular matrix fragmentation underlying AAD [12]. In particular, several lines of evidence have shown that MMP9 (collagenase type IV or gelatinase B) is activated in human aortic aneurysms [13-16]. Instead, less is known about MMP8 (neutrophil collagenase I) in aortic disease.

Several studies have demonstrated an association between aortic pathology and the circulating levels of MMPs [17]. The plasma levels of MMP8 and MMP9 have also been shown to increase in AAD compared to healthy controls and to selected patients with acute coronary syndromes [18-21]. However, the utility of circulating MMP8 or MMP9 for the diagnosis of AAD in the ED depends on their actual plasma levels in the far broader spectrum of patients with clinically suspected AAD.

To evaluate the diagnostic performance of plasma MMP8 and MMP9, their levels were evaluated in a prospective cohort of patients managed in the ED for suspected AAD. The diagnostic performance of MMP8 and MMP9 was also compared to that of D-dimer, the only routinely available circulating marker relevant to AAD.

\section{Materials and methods \\ Study population}

The present study was approved by the local Ethics Committee (Comitato Etico Interaziendale A.O.U. San Giovanni Battista di Torino e A.O. C.T.O. Maria Adelaide di Torino) and was performed in accordance with the Declaration of Helsinki (1964). All patients included in the study provided their informed consent (i) to enrolment and (ii) to publication of scientific results. The plasma levels of MMP8 and MMP9 were assayed in consecutive patients evaluated for suspected AAD in the ED of the Molinette Hospital of Turin, Italy, for a total of 26 months starting from June 2010. Blood samples for MMP dosage were obtained in the ED at the time of routine clinical evaluation. All patients included in the study were evaluated within 24 hours after symptom onset.

Patients were eligible to the study if all the following criteria were met: (i) clinical presentation suggestive of AAD (chest pain, abdominal pain, back pain, syncope or symptoms of perfusion deficit), as indicated by the 2010 guidelines of the American Heart Association [22]; (ii) order of an urgent chest and abdomen CT with contrast by the caring physician to expressly rule out $\mathrm{AAD}$; (iii) informed consent of the participant. To confirm appropriateness of enrolment, cases were subsequently re-evaluated by independent reviewers based on clinical charts and written requests for urgent $\mathrm{CT}$ originally filled out by the caring physician. Reviewers were blinded to the results of CT scan, blood tests and final diagnosis. Final alternative diagnoses were based on patient dismissal for hospitalized patients and on ED dismissal for outpatients.

\section{Matrix metalloproteinases}

Blood samples were obtained from all patients in EDTAcontaining tubes during their routine medical evaluation in the ED, when the other blood samples for routine diagnostic tests were drawn, and immediately sent to the laboratory. Plasma was obtained by centrifugation at 4,000 $\mathrm{rpm}$ for 5 minutes and stored at $-80^{\circ} \mathrm{C}$ until further processing. Plasma levels of MMP8 and MMP9 were measured by ELISA (Amersham ${ }^{\mathrm{TM}}$; GE Healthcare, Chalfont St Giles, UK). The assay is based on a two-site ELISA sandwich format using two antibodies (for capture and detection) directed against different epitopes of MMPs. The precision analysis for measurement of MMP8 and MMP9 yielded coefficients of variation (CV\%) of $2.3 \%$ and $5.5 \%$, respectively for within assay tests, and of $2.5 \%$ and $9.8 \%$ respectively for between-assay tests.

\section{Biochemical analyses}

Creatinine, troponin $\mathrm{T}$, lactate dehydrogenase (LDH) and C-reactive protein (CRP) were measured with the automated Cobas C8000 chemistry analyzers (Roche Diagnostics GmbH, Mannheim, Germany). D-dimer levels were measured with the automated STA LIATEST ${ }^{\mathrm{TM}}$ D-DI, based on latex agglutination (Diagnostica Stago for Roche Diagnostics GmbH, Mannheim, Germany).

\section{Statistical analysis}

Statistical analysis was performed with GraphPad Prism Software version 5.0 (GraphPad Software, San Diego, CA, USA). Data are presented as median and interquartile range (IQR), as the distribution of all biochemical variables (including MMP8 and MMP9) in the study population was not normal. Statistical tests used in the study were nonparametric Mann-Whitney $U$ test, nonparametric Dunn's test for multiple comparisons, Fisher's exact test and nonparametric Spearman correlation. Statistical comparison of different ROC curves was performed as previously described [23]. $P$ values lower than 0.05 were considered as statistically significant. 


\section{Results}

\section{Patient cohort}

In the study period, 186 patients managed in the ED for suspected AAD were eligible for the study. The number of enrolled patients was 126 (67.7\%). In these individuals, chief complaints were chest pain (60\%), abdominal pain (17\%), back pain (30\%), syncope (5\%) and other symptoms $(17 \%)$, in line with previous reports [3]. In this cohort, AAD was finally diagnosed in 52 patients (41.3\%), including 32 cases of Stanford type A and 20 cases of Stanford type B AAD. AAD was initially suspected but finally ruled out by CT scan in 74 patients $(58.7 \%)$. In these individuals, alternative final diagnoses included aortic aneurysm without signs of dissection $(n=16)$, inflammatory disease $(n=6)$, acute coronary syndrome $(n=5)$, other diagnoses $(n=8)$ and uncertain diagnoses $(n=39)$. The demographic and clinical characteristics of enrolled individuals are presented in Table 1.

\section{Plasma levels of MMP8 and MMP9}

The routine biochemical profile of patients with AAD and of patients receiving an alternative final diagnosis is presented in Table 2. Median D-dimer levels were 7.16 $\mu \mathrm{g} / \mathrm{ml}$ (2.81 to 18.70$)$ in patients with AAD and $1.34 \mu \mathrm{g} /$ $\mathrm{ml}(0.35$ to 2.31$)$ in patients receiving an alternative final diagnosis $(P<0.0001)$, in line with previous reports $[6,7]$. Also LDH was significantly higher in AAD compared to controls $(P=0.02)$. No significant differences were observed in the other biochemical variables.

Median MMP8 levels were $36.4 \mathrm{ng} / \mathrm{ml}$ (24.8 to 69.3) in patients with AAD and $13.2 \mathrm{ng} / \mathrm{ml}$ (8.1 to 31.8$)$ in patients receiving a final alternative diagnosis $(P<0.0001$, Figure 1a). MMP8 levels were $39.9 \mathrm{ng} / \mathrm{ml}$ (26.8 to 72.3 ) in patients with Stanford type A AAD and $34.2 \mathrm{ng} / \mathrm{ml}$ (14.7 to 64.2$)$ in patients with Stanford type B AAD $(P=$
0.32). MMP8 levels of control patients according to alternative final diagnoses are reported in Table 3. In patients receiving an alternative final diagnosis, the highest levels of plasma MMP8 were observed in individuals affected by an inflammatory disease. Of note, plasma MMP8 was not increased in patients with uncomplicated aortic aneurysm, suggesting that aortic dilation per se is not sufficient to significantly increase the circulating levels of MMP8 in this patient population.

Median MMP9 levels were $169.2 \mathrm{ng} / \mathrm{ml}$ (93.0 to 261.8) in patients with AAD and $80.5 \mathrm{ng} / \mathrm{ml}$ (41.8 to 140.6) in patients receiving a final alternative diagnosis $(P=0.0001$, Figure 1b). Median MMP9 levels were 204.9 ng/ml (104.1 to 296.3) in patients with Stanford type A dissection and $126.6 \mathrm{ng} / \mathrm{ml}$ (70.91 to 197.0$)$ in patients with type B dissection $(P=0.13)$. Plasma MMP9 levels of control patients according to alternative diagnoses are reported in Table 3. In patients receiving an alternative final diagnosis, the highest levels of plasma MMP9 were also observed in individuals affected by an inflammatory disease. Of note, plasma MMP9 was not increased in patients with uncomplicated aortic aneurysm, suggesting that aortic dilation per se is not sufficient to significantly increase circulating levels of MMP9 in this patient population.

\section{Correlation of plasma MMPs with CRP and D-dimer}

Plasma levels of MMP8 and MMP9 were highly correlated (Figure 1c, Spearman $r=0.63, P<0.0001$ ). Neither plasma MMP8 nor plasma MMP9 correlated with creatinine. Plasma MMP8 presented a slight albeit significant correlation with CRP (Spearman $r=0.22$, $P=0.022)$ and a stronger correlation with $\mathrm{D}$-dimer (Spearman $r=0.32, P<0.001)$. Also MMP9 correlated with both CRP (Spearman $r=0.29, P=0.003$ ) and Ddimer (Spearman $r=0.27, P=0.005$ ).

Table 1 Demographic and nosological characteristics of enrolled patients.

\begin{tabular}{|c|c|c|c|}
\hline & AAD & Alternative diagnosis & $P$ \\
\hline \multirow[t]{8}{*}{$\mathrm{N}$} & $52(41.3 \%)$ & $74(58.7 \%)$ & \\
\hline & Stanford & Alternative diagnoses: & \\
\hline & classification: & - Uncomplicated aortic aneurysm (16) & \\
\hline & - type A AAD (32) & - Inflammatory disease (6) & \\
\hline & - type B AAD (20) & - Pneumonia (3), pericarditis (1), pancreatitis (1), urinary tract infection (1) & \\
\hline & & - Acute coronary syndrome (5) & \\
\hline & & - Other diagnoses (8) & \\
\hline & & - Uncertain diagnoses (39) & \\
\hline Gender (M/F) & $40 / 12$ & $49 / 25$ & 0.24 \\
\hline Age (years) & $66.3 \pm 1.9$ & $64.0 \pm 1.7$ & 0.39 \\
\hline Hypertension & $31(59.6 \%)$ & $44(59.5 \%)$ & 1.00 \\
\hline Diabetes & $1(1.9 \%)$ & $11(14.9 \%)$ & 0.02 \\
\hline
\end{tabular}

Age is reported as mean \pm standard deviation. $P$ values are calculated with Fisher's exact test. AAD, acute aortic dissection. 
Table 2 Biochemical profile of enrolled patients.

\begin{tabular}{|c|c|c|c|}
\hline & AAD & Alternative diagnosis & $P$ \\
\hline $\begin{array}{l}\text { Creatinine } \\
(\mathrm{mg} / \mathrm{dl})\end{array}$ & $\begin{array}{c}1.02(0.86-1.32)[\mathrm{N}= \\
48]\end{array}$ & $\begin{array}{c}0.99(0.77-1.31)[\mathrm{N}= \\
71]\end{array}$ & 0.21 \\
\hline LDH (IU/I) & $415(370-651)[\mathrm{N}=23]$ & $371(329-424)[N=42]$ & 0.02 \\
\hline $\begin{array}{l}\text { Troponin- } \\
(\mu \mathrm{g} / \mathrm{dl})\end{array}$ & $\begin{array}{c}0.010(0.006-0.029)[\mathrm{N} \\
=45]\end{array}$ & $\begin{array}{c}0.010(0.008-0.013)[\mathrm{N} \\
=67]\end{array}$ & 0.69 \\
\hline CRP (mg/dl) & $4.4(1.6-34.3)[N=40]$ & $5.2(0.9-17.5)[\mathrm{N}=63]$ & 0.36 \\
\hline $\begin{array}{l}\text { D-dimer ( } \mu \mathrm{g} / \\
\mathrm{ml})\end{array}$ & $\begin{array}{c}7.16(2.81-18.70)[\mathrm{N}= \\
42]\end{array}$ & $\begin{array}{c}1.34(0.35-2.31)[\mathrm{N}= \\
61]\end{array}$ & 0.0001 \\
\hline
\end{tabular}

Values are presented as median and interquartile range (IQR). $\mathrm{N}$ represents the sample number for each biochemical value. $P$ values are calculated with nonparametric Mann-Whitney $U$ test. AAD, acute aortic dissection; CRP, Creactive protein; $L D H$, lactate dehydrogenase.

\section{Receiver-operating characteristics curve analysis of plasma MMP8 and MMP9}

The receiver-operating characteristics (ROC) curves of MMP8, MMP9 and D-dimer for the diagnosis of AAD are presented in Figure 2. For D-dimer, the AUC on ROC analysis for patients with AAD was 0.87 (95\% CI, 0.80 to 0.94 ) versus all controls, in line with previous reports [7]. Using a cutoff of $0.50 \mu \mathrm{g} / \mathrm{ml}, \mathrm{D}$-dimer showed a sensitivity of $97.6 \%$ (95\% CI, $87.4 \%$ to $99.9 \%$ ) and a specificity of $32.8 \%$ ( $95 \%$ CI, $21.3 \%$ to $46.0 \%)$. In the study cohort, D-dimer levels were $<0.50 \mu \mathrm{g} / \mathrm{ml}$ in $1 /$ $42(2.4 \%)$ patients with AAD (false negatives) and in 20/ 61 (32.8\%) patients without AAD (true negatives).

For MMP8, the AUC on ROC analysis for patients with AAD was 0.75 (95\% CI, 0.66 to 0.84 ) versus all controls, 0.75 (95\% CI, 0.59 to 0.91$)$ versus aortic aneurysm without dissection, 0.67 ( $95 \% \mathrm{CI}, 0.42$ to 0.91 ) versus inflammatory disease, 0.82 (95\% CI, 0.69 to 0.95 ) versus acute coronary syndrome, 0.66 (95\% CI, 0.44 to $0.88)$ versus other diagnoses and 0.82 (95\% CI, 0.73 to 0.91 ) versus uncertain diagnoses. Using a cutoff of 3.6 $\mathrm{ng} / \mathrm{ml}$, plasma MMP8 had a sensitivity of $100.0 \%(95 \%$ CI, $93.2 \%$ to $100.0 \%)$ and a specificity of $9.5 \%$ (95\% CI, $3.9 \%$ to $18.5 \%)$. In the study cohort, plasma MMP8 levels were $<3.6 \mathrm{ng} / \mathrm{ml}$ in $0 / 52$ patients $(0 \%)$ with AAD (false negatives) and in $7 / 74(9.5 \%)$ patients without AAD (true negatives).

For MMP9, the AUC on ROC analysis for patients with AAD was 0.70 (95\% CI, 0.61 to 0.80 ) versus all controls, 0.77 (95\% CI, 0.63 to 0.91 ) versus aortic aneurysm without signs of dissection, 0.69 (95\% CI, 0.45 to 0.93 ) versus inflammatory disease, 0.73 (95\% CI, 0.56 to 0.89 ) versus acute coronary syndrome, 0.54 ( $95 \% \mathrm{CI}, 0.31$ to 0.78$)$ versus other diagnoses and 0.76 (95\% CI, 0.66 to 0.86 ) versus uncertain diagnoses. Using a cutoff of $20.0 \mathrm{ng} / \mathrm{ml}$, plasma MMP9 had a sensitivity of $96.2 \%$ (95\% CI, $86.8 \%$ to $99.5 \%$ ) and a specificity of $16.2 \%$ (95\% CI, $8.7 \%$ to $26.6 \%$ ). In the study cohort, plasma MMP9 levels were <20.0 ng/

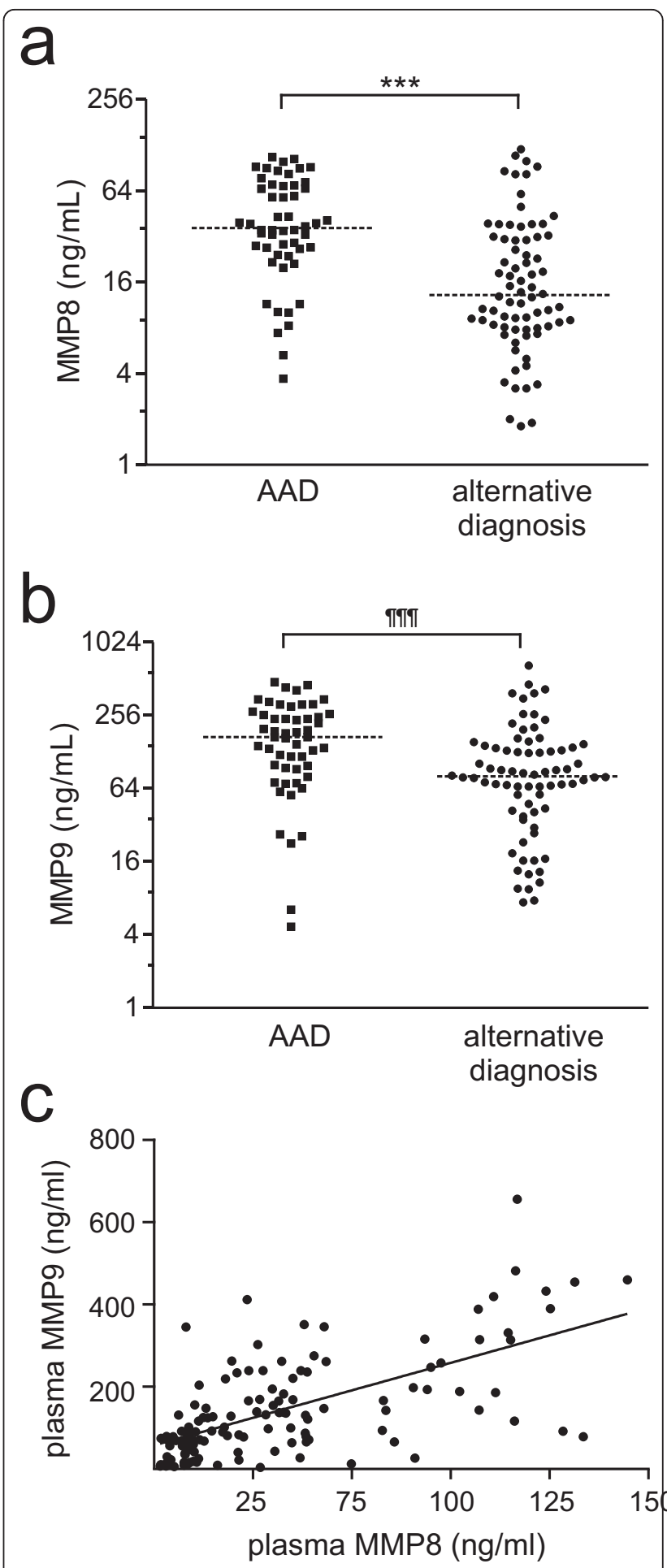

Figure 1 Plasma levels (ng/ml) of MMP8 (a) and MMP9 (b) in patients with acute aortic dissection (AAD) and in patients receiving a final alternative diagnosis. $Y$-axis: $\log _{2}$ scale. ${ }^{* *} P$ $<0.0001$, ${ }^{\text {ศศ } P} P=0.0001$ by nonparametric Mann-Whitney $U$ test. (c) Correlation of plasma MMP8 and plasma MMP9 in enrolled patients. MMP, matrix metalloproteinase. 
Table 3 Plasma levels of MMP8 and MMP9 in acute aortic dissection versus alternative diagnoses.

\begin{tabular}{|c|c|c|c|}
\hline & $\mathrm{N}$ & MMP8 (ng/ml) & MMP9 (ng/ml) \\
\hline Acute aortic dissection & 52 & $36.4 \underset{f}{(24.8-69.3)^{a,}}$ & $169.2 \underset{\mathrm{g}}{(93.0-261.8)^{\mathrm{e}}}$ \\
\hline $\begin{array}{l}\text { Uncomplicated aortic } \\
\text { aneurysm }\end{array}$ & 16 & $10.7(4.6-33.9)^{\mathrm{a}}$ & $54.4(20.9-96.6)^{e, b}$ \\
\hline Inflammatory disease & 6 & $\begin{array}{c}60.8(31.6- \\
105.5)^{d}\end{array}$ & $294.0 \underset{b, c}{(125.8-407.6)}$ \\
\hline Acute coronary syndrome & 5 & $12.90(8.1-29.0)$ & $92.4(58.1-152.5)$ \\
\hline Other diagnoses & 8 & $17.6(12.9-69.3)$ & $137.1(63.3-340.5)$ \\
\hline Uncertain diagnoses & 39 & $10.5(7.3-22.9)^{\mathrm{d}, \mathrm{f}}$ & $78.8(35.4-127.6)^{c, g}$ \\
\hline
\end{tabular}

Values are presented as median and interquartile range (IQR). ${ }^{\mathrm{a}, \mathrm{b}, \mathrm{c}} \mathrm{p}<0.05 ; \mathrm{d}, \mathrm{e} P$ $<0.01 ;$ f,g $p<0.001$ by nonparametric Dunn's multiple comparison test. MMP, matrix metalloproteinase.

$\mathrm{ml}$ in 2/52 (3.8\%) patients with AAD (false negatives) and in $12 / 74$ (16.2\%) patients without AAD (true negatives).

\section{Combination of plasma MMP8 with D-dimer}

Next, we tested the hypothesis that a combined use of plasma MMP8 and D-dimer may: (i) increase the diagnostic accuracy of MMP8 alone, and (ii) safely rule out AAD in a clinically significant proportion of patients. Indeed, calculation of the AUC on ROC analysis demonstrated better performance of a combination of MMP8 and D-dimer than plasma MMP8 alone $(P<0.05$, Figure 2 and Table 4). Table 5 reports the negative predictive values (NPV) obtained by combination of three different diagnostic cutoffs for MMP8 and D-dimer. Of note, the NPV of plasma MMP8 at the cutoff of $11.0 \mathrm{ng} / \mathrm{ml}$ increased from $84.2 \%$ when used alone to $100 \%$ when used in association with any proposed D-dimer cutoff $(0.5,1.0$ or $2.0 \mu \mathrm{g} / \mathrm{ml})$. Furthermore, combination of MMP8 $<11.0 \mathrm{ng} / \mathrm{ml}$ with any D-dimer cutoff identified up to 22 true negatives in the study cohort and was not associated with false negatives, as compared to 6 false negatives with MMP8 $<11.0$ $\mathrm{ng} / \mathrm{ml}$ alone. These findings indicate that a combined use of plasma MMP8 and D-dimer represents a promising strategy to safely rule out AAD in a significant proportion of patients in the ED.

\section{Discussion}

The present study is, to the best of our knowledge, the first to evaluate the levels of plasma MMP8 and MMP9 in a prospective cohort of patients managed in the ED for suspected $A A D$, and thus to directly estimate the actual diagnostic value of these markers. Previous casecontrol studies have reported increased plasma levels of MMP8 and MMP9 in AAD [18,20]. These studies had a retrospective design and focused on selected groups as controls, such as normal individuals and patients with acute coronary syndrome. However, the differential diagnoses of AAD are multiple and highly heterogeneous [24]. In the present ED-based study cohort, for instance, $6.8 \%$ of patients without AAD were finally diagnosed with acute coronary syndrome, while $8.1 \%$ received a diagnosis of inflammatory disease such as pancreatitis or pneumonia, thus reflecting the wide spectrum of differential diagnosis.

In the present study, median plasma levels of MMP8 and MMP9 were respectively 2.8-fold and 2.1-fold higher in AAD than in patients receiving alternative

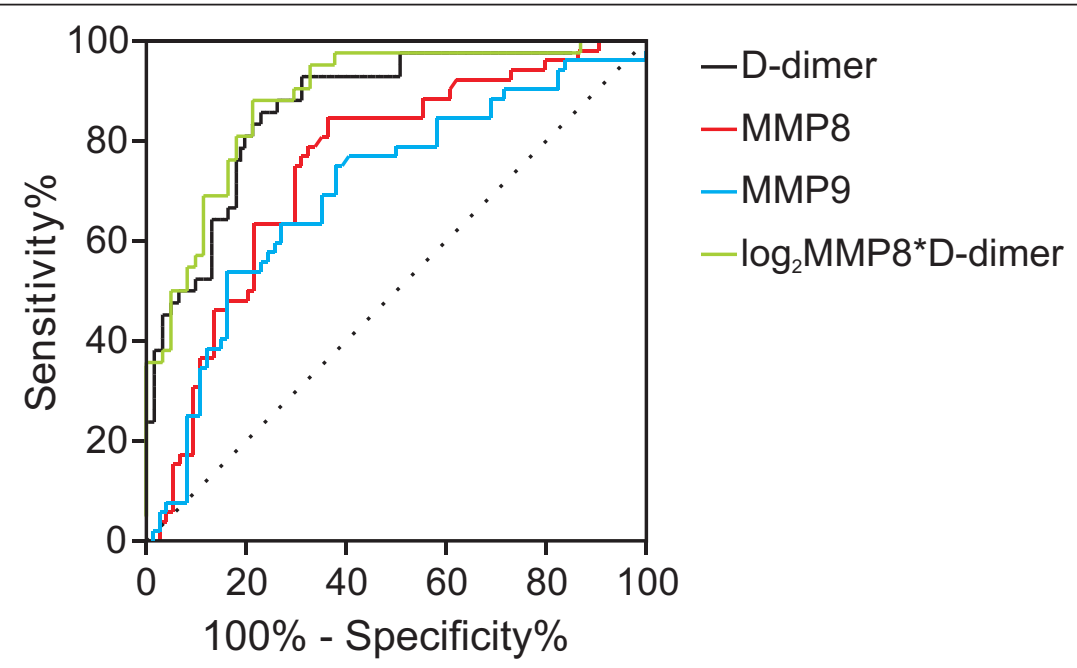

Figure 2 Receiver-operating characteristics (ROC) curve of plasma MMP8, plasma MMP9, D-dimer and combination of MMP8 and Ddimer $\left(\log _{2}\right.$ MMP8*D-dimer) for patients with acute aortic dissection versus subjects receiving an alternative final diagnosis. MMP, matrix metalloproteinase. 
Table 4 ROC analysis for plasma MMP8, D-dimer and their combination.

\begin{tabular}{|c|c|c|c|c|}
\hline & $\begin{array}{c}\text { AUC } \\
(95 \% \mathrm{Cl})\end{array}$ & Cutoff & $\begin{array}{c}\text { Sensitivity \% } \\
(95 \% \mathrm{Cl})\end{array}$ & $\begin{array}{c}\text { Specificity \% } \\
(95 \% \mathrm{Cl})\end{array}$ \\
\hline MMP8 & $\begin{array}{c}0.75^{a, b, c} \\
(0.66-0.84) \\
\end{array}$ & $\begin{array}{c}>3.6 \\
\mathrm{ng} / \mathrm{ml}\end{array}$ & $\begin{array}{c}100 \% \\
(93.2 \%-100.0 \%)\end{array}$ & $\begin{array}{c}9.5 \% \\
(3.9 \%-18.5 \%)\end{array}$ \\
\hline DD & $\begin{array}{c}0.87^{\mathrm{a}} \\
(0.80-0.94)\end{array}$ & $\begin{array}{l}>0.50 \\
\mu \mathrm{g} / \mathrm{ml}\end{array}$ & $\begin{array}{c}97.6 \% \\
(87.4 \%-99.9 \%)\end{array}$ & $\begin{array}{c}32.8 \% \\
(21.3 \%-46.0 \%)\end{array}$ \\
\hline DD*MMP8 & $\begin{array}{c}0.87^{b} \\
(0.80-0.94)\end{array}$ & $>2.44$ & $\begin{array}{c}100 \% \\
(91.6 \%-100.0 \%)\end{array}$ & $\begin{array}{c}16.4 \% \\
(8.2 \%-28.1 \%)\end{array}$ \\
\hline DD* $\log _{2}(\mathrm{MMP} 8)$ & $\begin{array}{c}0.89^{c} \\
(0.82-0.95)\end{array}$ & $>0.77$ & $\begin{array}{c}100 \% \\
(91.6 \%-100.0 \%)\end{array}$ & $\begin{array}{c}13.1 \% \\
(5.8 \%-24.2 \%)\end{array}$ \\
\hline
\end{tabular}

${ }^{\mathrm{a}} P=0.048,{ }^{\mathrm{b}} P=0.034,{ }^{\mathrm{c}} P=0.018$. AUC, area under the curve; DD, D-dimer; MMP, matrix metalloproteinase; ROC, receiver-operating characteristics.

diagnoses. The plasma levels of MMP8 and MMP9 were highly correlated, indicating that leakage of these proteins into the bloodstream relates to the same biological processes. As plasma MMP8 and MMP9 were similar in patients with uncomplicated aortic aneurysm and in patients with other unspecific diagnoses having a regular aortic size, aortic dilation per se does not appear as a major determinant of plasma MMP8 and MMP9 in the selected population of patients.

Based on AUC analysis, the overall performance of plasma MMP8 and MMP9 for the diagnosis of AAD is limited and inferior to that of D-dimer, the only marker of AAD currently available in clinical practice [6,7]. This is largely due a substantial variability of plasma MMP8 and MMP9 in patients without AAD, which leads to negligible specificity and positive predictive value of these markers. In particular, high circulating levels of MMP8 and MMP9 were found in patients affected by inflammatory conditions, such as pancreatitis and pneumonia. This is in line with the notion that MMP8 and MMP9 are expressed by neutrophils and with previous reports that plasma MMP9 is increased in acute pancreatitis

Table 5 Negative predictive value of plasma MMP8 in combination with D-dimer.

\begin{tabular}{|c|c|c|c|c|c|}
\hline \multirow[t]{2}{*}{ NPV } & \multirow[b]{2}{*}{ AND } & \multicolumn{4}{|c|}{ D-dimer $(\mu \mathrm{g} / \mathrm{ml})$} \\
\hline & & Any value & $<0.5$ & $<1.0$ & $<2.0$ \\
\hline & $<3.6$ & $\begin{array}{c}100 \% \\
\text { TN 7, FN } 0\end{array}$ & $\begin{array}{c}100 \% \\
\text { TN 1, FN } \\
0\end{array}$ & $\begin{array}{c}100 \% \\
\text { TN 1, FN } \\
0\end{array}$ & $\begin{array}{c}100 \% \\
\text { TN 3, FN } \\
0\end{array}$ \\
\hline \multirow[t]{3}{*}{$\begin{array}{l}\text { MMP8 (ng/ } \\
\mathrm{ml})\end{array}$} & $<11.0$ & $\begin{array}{c}84.2 \% \\
\text { TN } 32, \text { FN } \\
6\end{array}$ & $\begin{array}{c}100 \% \\
\text { TN } 12, \mathrm{FN} \\
0\end{array}$ & $\begin{array}{c}100 \% \\
\text { TN 14, FN } \\
0\end{array}$ & $\begin{array}{c}100 \% \\
\text { TN 22, FN } \\
0\end{array}$ \\
\hline & $<30.0$ & $\begin{array}{c}73.2 \% \\
\text { TN } 52, \text { FN } \\
19\end{array}$ & $\begin{array}{c}94.1 \% \\
\text { TN } 16, \mathrm{FN} \\
1\end{array}$ & $\begin{array}{c}95.5 \% \\
\text { TN } 21, \mathrm{FN} \\
1\end{array}$ & $\begin{array}{c}93.9 \% \\
\text { TN 31, FN } \\
2\end{array}$ \\
\hline & $\begin{array}{l}\text { Any } \\
\text { value }\end{array}$ & & $\begin{array}{c}95.2 \% \\
\text { TN 20, FN } \\
1\end{array}$ & $\begin{array}{c}96.6 \% \\
\text { TN 28, FN } \\
1\end{array}$ & $\begin{array}{c}93.3 \% \\
\text { TN } 42, \mathrm{FN} \\
3\end{array}$ \\
\hline
\end{tabular}

Three representative cutoffs are presented for each biomarker. NPV, negative predictive value (\%); TN, true negatives; FN, false negatives; MMP, matrix metalloproteinase.
$[19,25]$. Indeed, both plasma MMP8 and MMP9 slightly but significantly correlated with CRP levels in the present study population.

The present results clearly demonstrate that plasma MMP8 and MMP9 are unsuitable per se to diagnose AAD in patients presenting to the ED with suggestive symptoms. Instead, our data indicate that low plasma levels of MMP8 could be used to rule out AAD. For instance, rule out of AAD in the presence of MMP8 $<3.6 \mathrm{ng} / \mathrm{ml}$ could avoid 7/126 urgent CT scans in the study cohort, corresponding to a $5.6 \%$ reduction in the number of urgent $\mathrm{CT}$ scans performed in the ED for suspected AAD. The CT scans in question were performed in four patients with uncomplicated aortic aneurysm and in three patients with other unspecific diagnoses, and did not provide any additional clinical benefit. Several studies have shown that also D-dimer has favorable rule-out properties for AAD. In our study cohort, rule out of $\mathrm{AAD}$ in the presence of $\mathrm{D}$-dimer $<0.50 \mu \mathrm{g} / \mathrm{ml}$ could avoid 21/103 urgent CT scans, corresponding to a $20.4 \%$ reduction in the number of urgent CT scans performed in the ED for suspected AAD. However, the latter approach would lead to one missed diagnosis of Stanford type B AAD, with presumably dramatic clinical consequences. These data indicate that, although D-dimer shows a better ROC curve than plasma MMP8 for the diagnosis of AAD, MMP8 may provide better sensitivity and lower rates of false negatives if a sufficiently low cutoff is applied.

A major finding of the present study is that combination of low plasma MMP8 and low D-dimer has the potential to safely rule out AAD. In our cohort, combination of plasma MMP8 $<11.0 \mathrm{ng} / \mathrm{ml}$ and D-dimer $<1.0$ or $<2.0 \mu \mathrm{g} / \mathrm{ml}$ (that is individually suboptimal cutoffs for both markers) provided a NPV of $100 \%$. Rule out of AAD with MMP8 $<11.0 \mathrm{ng} / \mathrm{ml}$ and D-dimer $<1.0$ or $<2.0 \mu \mathrm{g} / \mathrm{ml}$ could avoid respectively $14 / 103$ or $22 / 103$ urgent CT scans, corresponding to a $13.6 \%$ or $21.4 \%$ reduction in the number of urgent $\mathrm{CT}$ scans for suspected AAD, without any missed diagnosis of AAD. In order to limit costs, plasma MMP8 levels might be measured only in patients 
with elevated D-dimer levels. In this scenario, turnaround time could be limited by applying rapid point-of-care testing of D-dimer in the ED [26].

Taken together, results from the present study indicate that the plasma levels of MMP8 may assist emergency physicians in evaluating the necessity to perform urgent secondary imaging in patients with clinical presentations suggestive of AAD. Extrapolating data from the study cohort, plasma MMP8 alone has the potential to avoid one urgent CT scan every twenty patients with a clinical suspicion of AAD, while combination of MMP8 and Ddimer could avoid as much as one urgent $\mathrm{CT}$ scan every five patients. In the context of a continuous increase in the rate of CT use in EDs (for example 5- and 10-fold increases in a decade for the categories of chest and abdominal pain), the benefits of such an approach will clearly depend on the respective site-specific costs, availability and turnaround times of biochemical assays and urgent secondary imaging [27].

While the struggle for a specific aortic biomarker continues, validation of robust rule-out approaches may pave our way toward a safer and more cost-effective management of suspected AAD in EDs while avoiding an exponential increase in urgent $\mathrm{CTs}$.

\section{Limitations}

A number of limitations apply to the present findings. First, data on diagnostic accuracy clearly depend on the enrolled population of patients. We applied for enrolment the diagnostic algorithm suggested by the American Heart Association [22]. However, the diagnostic performance of this algorithm is largely unknown, especially in the context of EDs [28]. Furthermore, even compliance with these guidelines does not eliminate a substantial amount of subjectivity in the clinical suspicion of AAD and thus in the decision of the caring physician to perform an urgent CT. Second, we acknowledge that sample size constitutes a significant limitation of the present study. In particular, we provide proof-of-concept that combination of D-dimer with plasma MMP8 at individually suboptimal cutoffs could provide a better rule-out profile than D-dimer alone. However, D-dimer was measured in only 103/126 patients enrolled in the present study $(81.7 \%)$. Hence, conclusive demonstration of statistical superiority requires a substantial increase in patient number. Given the low incidence of AAD, multicenter studies are presumably needed for the purpose.

\section{Conclusions}

In a prospectively enrolled cohort of patients evaluated in the ED, plasma MMP8 and MMP9 showed negligible specificity for the diagnosis of AAD. Plasma MMP8 demonstrated better diagnostic performance than plasma MMP9, but both MMP8 and MMP9 were inferior to D-dimer on
ROC analysis. However, use of a low cutoff for plasma MMP8 $(3.6 \mathrm{ng} / \mathrm{ml})$ provided high sensitivity to rule out AAD and allowed a potential $5 \%$ reduction in urgent secondary imaging. Combined use of plasma MMP8 and D-dimer at individually suboptimal cutoffs provided optimal negative predictive value and allowed a potential $20 \%$ reduction in urgent secondary imaging.

\section{Key messages}

- While plasma MMP8 and MMP9 lack specificity for AAD, low plasma MMP8 levels have satisfactory ruleout properties for AAD in the ED.

- Combination of D-dimer and plasma MMP8 could be used to avoid a significant amount of urgent secondary imaging in patients evaluated for suspected AAD in the ED.

\section{Abbreviations}

AAD: acute aortic dissection; AUC: area under the curve; CRP: C-reactive protein; CT: computed tomography; ED: emergency department; EDTA: ethylenediaminetetraacetic acid; ELISA: enzyme-linked immunosorbent assay; IQR: interquartile range; LDH: lactate dehydrogenase; MMP8: matrix metalloproteinase-8; MMP9: matrix metalloproteinase-9; NPV: negative predictive value; ROC: receiver-operating characteristics.

\section{Authors' contributions}

FG enrolled patients, acquired and analyzed the data. MLo, MLu and MM managed plasma samples and performed biochemical assays. SB, ES, EL and CM enrolled patients. GM and EH coordinated sample collection and biochemical assays. FM designed and coordinated the research, enrolled patients, analyzed and interpreted the data, wrote the manuscript. All authors have read and approved the manuscript for publication.

\section{Competing interests}

The authors declare that they have no competing interests.z

\section{Acknowledgements}

We would like to thank all the colleagues of the S.C. Medicina d'Urgenza for their work and collaboration.

\section{Author details}

${ }^{1}$ S.C. Medicina d'Urgenza, Molinette Hospital, A.O. Città della Salute e della Scienza di Torino, Corso Bramante, 88, 10126 Torino, Italy. ${ }^{2}$ S.C. Chimica Clinica, Molinette Hospital, A.O. Città della Salute e della Scienza di Torino, Corso Bramante, 88, 10126 Torino, Italy. ${ }^{3}$ Molecular Biotechnology Center, Università degli Studi di Torino, Via Nizza, 52, 10126 Torino, Italy.

Received: 10 October 2012 Revised: 10 December 2012

Accepted: 20 February 2013 Published: 25 February 2013

\section{References}

1. Tsai TT, Trimarchi S, Nienaber CA: Acute aortic dissection: perspectives from the International Registry of Acute Aortic Dissection (IRAD). Eur J Vasc Endovasc Surg 2009, 37:149-159.

2. Nienaber CA, Powell JT: Management of acute aortic syndromes. Eur Heart J 2012, 33:26-35b.

3. Hagan PG, Nienaber CA, Isselbacher EM, Bruckman D, Karavite DJ, Russman PL, Evangelista A, Fattori R, Suzuki T, Oh JK, Moore AG, Malouf JF, Pape LA, Gaca C, Sechtem U, Lenferink S, Deutsch HJ, Diedrichs H, Marcos y Robles J, Llovet A, Gilon D, Das SK, Armstrong WF, Deeb GM, Eagle KA: The International Registry of Acute Aortic Dissection (IRAD): new insights into an old disease. JAMA 2000, 283:897-903.

4. Clouse WD, Hallett JW Jr, Schaff HV, Spittell PC, Rowland CM, IIstrup DM, Melton LJ: Acute aortic dissection: population-based incidence compared 
with degenerative aortic aneurysm rupture. Mayo Clin Proc 2004, 79:176-180.

5. Meszaros I, Morocz J, Szlavi J, Schmidt J, Tornoci L, Nagy L, Szep L: Epidemiology and clinicopathology of aortic dissection. Chest 2000, 117:1271-1278.

6. Marill KA: Serum D-dimer is a sensitive test for the detection of acute aortic dissection: a pooled meta-analysis. J Emerg Med 2008, 34:367-376.

7. Shimony A, Filion KB, Mottillo S, Dourian T, Eisenberg MJ: Meta-analysis of usefulness of d-dimer to diagnose acute aortic dissection. Am J Cardiol 2011, 107:1227-1234.

8. Suzuki T, Katoh $\mathrm{H}$, Tsuchio $\mathrm{Y}$, Hasegawa A, Kurabayashi M, Ohira A, Hiramori K, Sakomura Y, Kasanuki H, Hori S, Aikawa N, Abe S, Tei C, Nakagawa Y, Nobuyoshi M, Misu K, Sumiyoshi T, Nagai R: Diagnostic implications of elevated levels of smooth-muscle myosin heavy-chain protein in acute aortic dissection. The smooth muscle myosin heavy chain study. Ann Intern Med 2000, 133:537-541.

9. Shinohara T, Suzuki K, Okada M, Shiigai M, Shimizu M, Maehara T, Ohsuzu F: Soluble elastin fragments in serum are elevated in acute aortic dissection. Arterioscler Thromb Vasc Biol 2003, 23:1839-1844.

10. Suzuki T, Distante A, Zizza A, Trimarchi S, Villani M, Salerno Uriarte JA, de Luca Tupputi Schinosa L, Renzulli A, Sabino F, Nowak R, Birkhahn R, Hollander JE, Counselman F, Bossone E, Eagle K: Preliminary experience with the smooth muscle troponin-like protein, calponin, as a novel biomarker for diagnosing acute aortic dissection. Eur Heart J 2008, 29:1439-1445

11. $\mathrm{Vu} T H$, Werb Z: Matrix metalloproteinases: effectors of development and normal physiology. Genes Dev 2000, 14:2123-2133.

12. Zhang $X$, Shen YH, LeMaire SA: Thoracic aortic dissection: are matrix metalloproteinases involved? Vascular 2009, 17:147-157.

13. Freestone T, Turner RJ, Coady A, Higman DJ, Greenhalgh RM, Powell JT: Inflammation and matrix metalloproteinases in the enlarging abdominal aortic aneurysm. Arterioscler Thromb Vasc Biol 1995, 15:1145-1151.

14. Tung WS, Lee JK, Thompson RW: Simultaneous analysis of 1176 gene products in normal human aorta and abdominal aortic aneurysms using a membrane-based complementary DNA expression array. J Vasc Surg 2001, 34:143-150.

15. Koullias GJ, Ravichandran P, Korkolis DP, Rimm DL, Elefteriades JA: Increased tissue microarray matrix metalloproteinase expression favors proteolysis in thoracic aortic aneurysms and dissections. Ann Thorac Surg 2004, 78:2106-2111.

16. Didangelos A, Yin X, Mandal K, Baumert M, Jahangiri M, Mayr M: Proteomics characterization of extracellular space components in the human aorta. Mol Cell Proteomics 2010, 9:2048-2062.

17. Golledge J, Tsao PS, Dalman RL, Norman PE: Circulating markers of abdominal aortic aneurysm presence and progression. Circulation 2008, 118:2382-2392.

18. Sangiorgi G, Trimarchi S, Mauriello A, Righini P, Bossone E, Suzuki T, Rampoldi V, Eagle KA: Plasma levels of metalloproteinases-9 and -2 in the acute and subacute phases of type $A$ and type B aortic dissection. J Cardiovasc Med (Hagerstown) 2006, 7:307-315.

19. Wen T, Liu L, Xiong GZ: Matrix metalloproteinase levels in acute aortic dissection, acute pancreatitis and other abdominal pain. Emerg Med J 2009, 26:715-718.

20. Li Y, Shao AZ, Jiang HT, Dong GH, Xu B, Yi J, Jing H: The prominent expression of plasma matrix metalloproteinase-8 in acute thoracic aortic dissection. J Surg Res 2010, 163:e99-104

21. Wen $D$, Zhou XL, Li JJ, Luo F, Zhang L, Gao LG, Wang LP, Song L, Sun K Zou YB, Zhang CN, Hui RT: Plasma concentrations of interleukin-6, Creactive protein, tumor necrosis factor- $a$ and matrix metalloproteinase- 9 in aortic dissection. Clin Chim Acta 2012, 413:198-202.

22. Hiratzka LF, Bakris GL, Beckman JA, Bersin RM, Carr VF, Casey DE, Eagle KA, Hermann LK, Isselbacher EM, Kazerooni EA, Kouchoukos NT, Lytle BW, Milewicz DM, Reich DL, Sen S, Shinn JA, Svensson LG, Williams DM: 2010 ACCF/AHA/AATS/ACR/ASA/SCA/SCAI/SIR/STS/SVM guidelines for the diagnosis and management of patients with Thoracic Aortic Disease: a report of the American College of Cardiology Foundation/American Heart Association Task Force on Practice Guidelines, American Association for Thoracic Surgery, American College of Radiology, American Stroke Association, Society of Cardiovascular Anesthesiologists, Society for Cardiovascular Angiography and Interventions, Society of Interventional Radiology, Society of Thoracic
Surgeons, and Society for Vascular Medicine. Circulation 2010, 121: e266-369.

23. Hanley JA, MCNeil BJ: The meaning and use of the area under a receiver operating characteristic (ROC) curve. Radiology 1982, 143:29-36.

24. Olsson C, Thelin S, Stahle E, Ekbom A, Granath F: Thoracic aortic aneurysm and dissection. Circulation 2006, 114:2611-2618.

25. Guo J, Xue P, Yang XN, Liu XB, Huang W, Xia Q: Serum matrix metalloproteinase- 9 is an early marker of pancreatic necrosis in patients with severe acute pancreatitis. Hepatogastroenterology 2012, 59:1594-1598.

26. Suzuki T, Distante A, Zizza A, Trimarchi S, Villani M, Salerno Uriarte JA, De Luca Tupputi Schinosa L, Renzulli A, Sabino F, Nowak R, Birkhahn R, Hollander JE, Counselman F, Vijayendran R, Bossone E, Eagle K: Diagnosis of acute aortic dissection by D-dimer: the International Registry of Acute Aortic Dissection Substudy on Biomarkers (IRAD-Bio) experience. Circulation 2009, 119:2702-2707.

27. Kocher KE, Meurer WJ, Fazel R, Scott PA, Krumholz HM, Nallamothu BK: National trends in use of computed tomography in the emergency department. Ann Emerg Med 2011, 58:452-462, e453.

28. Rogers AM, Hermann LK, Booher AM, Nienaber CA, Williams DM, Kazerooni EA, Froehlich JB, O'Gara PT, Montgomery DG, Cooper JV, Harris KM, Hutchison S, Evangelista A, Isselbacher EM, Eagle KA: Sensitivity of the aortic dissection detection risk score, a novel guideline-based tool for identification of acute aortic dissection at initial presentation: results from the international registry of acute aortic dissection. Circulation 2011, 123:2213-2218.

doi: $10.1186 / \mathrm{cc} 12536$

Cite this article as: Giachino et al:: Rule out of acute aortic dissection with plasma matrix metalloproteinase 8 in the emergency department. Critical Care 2013 17:R33.

\section{Submit your next manuscript to BioMed Central and take full advantage of:}

- Convenient online submission

- Thorough peer review

- No space constraints or color figure charges

- Immediate publication on acceptance

- Inclusion in PubMed, CAS, Scopus and Google Scholar

- Research which is freely available for redistribution

Submit your manuscript at www.biomedcentral.com/submit
C Biomed Central 